\title{
Maternal body mass index and feto-maternal outcome: a comparative study
}

\author{
N. Hemalatha*, Shanthini \\ Department of Obstetrics and Gynecology, Madras Medical College, Chennai, Tamil Nadu, India
}

Received: 25 January 2019

Accepted: 20 February 2019

\section{*Correspondence:}

Dr. N. Hemalatha,

E-mail: vbharu.92@gmail.com

Copyright: (C) the author(s), publisher and licensee Medip Academy. This is an open-access article distributed under the terms of the Creative Commons Attribution Non-Commercial License, which permits unrestricted non-commercial use, distribution, and reproduction in any medium, provided the original work is properly cited.

\section{ABSTRACT}

Background: Increasing BMI in women poses multiple threat of illness especially in the reproductive age group impacting pregnancy. Pregnant women with overweight and obesity are at a higher risk of developing complications at all stages of the physiological pregnancy. A focus on the methods to prevent this trend of increasing weight gain in adolescence is essential curb the complications due to obesity.

Methods: This prospective study was conducted in the Department of Obstetrics and Gynecology, Madras Medical College, Chennai. Written informed consent was obtained and pregnant women visiting the antenatal OP were registered. Detailed history taking and examination was carried out with the measurement of body mass index as weight in $\mathrm{kg} / \mathrm{height}$ in meter square. The women were followed up for the antepartum, intrapartum, post-partum variables and neonatal outcome.

Results: Two hundred pregnant women with high BMI $>25 \mathrm{~kg} / \mathrm{m}^{2}$ and two hundred pregnant women with normal BMI were selected and were followed prospectively. Present study showed an increased incidence of pre-eclampsia in patients with high BMI (28\% as compared to $8 \%$ of the normal BMI) and a higher incidence of Gestational diabetes mellitus among women with high BMI with a value of $27.5 \%$ compared to a value of $7.5 \%$ in women with normal BMI. Caesarean delivery was found in $54.5 \%$ of the high BMI mothers compared to $31.5 \%$ in normal BMI mothers. Postoperatively, wound gaping was found with an incidence of $4.5 \%$ in high BMI mothers. IUGR was found in $10 \%$ of babies of women with high BMI and still birth occurred in $2.5 \%$ of deliveries of high BMI mothers compared to $0.5 \%$ in mothers of normal BMI group.

Conclusions: The obstetrician needs to be well versed with dietary advice and life style pattern advice to the women of the reproductive age group in order to prevent the complications of high Body mass index in pregnancy. Its imperative to counsel these women about the pre-pregnancy loss of weight, healthy food and exercise, and healthy life style pattern during pregnancy in order to have a healthy outcome.

Keywords: Body mass index, Caesarean delivery, Feto-maternal outcome

\section{INTRODUCTION}

With the rapid rate of socio-economic development and socio-cultural changes, changes in dietary pattern and changes in lifestyle, increasing BMI has become a healthcare burden to the nation. This increasing rate of BMI has affected all age groups universally. It causes major medical ailments like hypertension, Diabetes, cardiovascular, neurovascular diseases, arthritis and causes a lot of morbidity and mortality. ${ }^{1}$ The World Health Organization and the National Institutes of Health define body mass index (BMI) less than 18.5 as underweight, 18.5-22.9 as normal weight, 23-24.9 as overweight and $\geq 25 \mathrm{BMI}$ as obesity. ${ }^{2}$ About $13 \%$ of the 
world's adult populations are obese. According to National Family Health Survey, the percentage of married women (15-49 years) who are overweight or obese increased from $11 \%$ (NFHS 2) to $15 \%$ (NFHS 3). ${ }^{3}$

Maternal obesity has been reported as a risk factor for various antenatal, intrapartum, postpartum and neonatal complications such as postdates, induction of labour, macrosomia, shoulder dystocia, prolonged duration of labour, increased blood loss, caesarean section rates and neonatal admissions. ${ }^{4}$

Many factors associated with perinatal morbidity and mortality are not amenable to intervention. Recent epidemiologic findings indicate that weight control may offer the potential for affecting gestational outcomes. A focus on the methods to prevent this trend of increasing weight gain in adolescence is essential curb the complications due to obesity.

The objective of the present study was to compare the antepartum, intrapartum, postpartum and neonatal outcome in pregnant mothers with high body mass index in the first trimester with those of normal body mass index and to find the incidence of complications in mothers with high body mass index.

\section{METHODS}

This prospective study was conducted in the Department of Obstetrics and Gynecology, Madras Medical College, Chennai. Written informed consent was obtained from all antenatal women who participated in the study. Detailed history taking and examination were carried out with the measurement of body mass index as weight in $\mathrm{kg} / \mathrm{height}$ in meter square.

\section{Inclusion criteria}

- Primi gravida pregnant mothers below 12 weeks of gestation.

\section{Exclusion criteria}

- Patients not willing for the study

- Multiple pregnancies

- Women with medical disorders

- Diabetes, hypertension.

Pregnant women visiting the antenatal op, in the early trimester after getting written consent were registered. Detailed history taking and examination were carried out with the measurement of body mass index as weight in $\mathrm{kg} /$ height in meter square.

The subjects were classified into 2 groups

- Group 1- Normal: BMI (20-24.9)

- Group 2- Overweight and obese (BMI 25 and above)
The women were followed up for the antepartum, intrapartum, post-partum variables and neonatal outcome.

The data were analysed for the 2 groups of patients in the study.

\section{Antenatal variables}

- Abortion, Preeclampsia, Gestational diabetes mellitus, Oligohydramnios, Abruptio placenta, Anaemia, PROM

\section{Intrapartum variables}

- Vaginal delivery, Caesarean section, Instrumental delivery

\section{Postpartum variables}

- PPH, Duration of hospital stay, Wound infection/gaping, Pyrexia, Lactational dysfunction

\section{Neonatal variables}

- $\quad$ IUGR, Preterm, Macrosomia (>4 kg), Post-term, Still birth, NICU Admission, Need for intubation.

\section{Statistical analysis}

Statistical comparison between data of cases (BMI>25) and controls $(\mathrm{BMI}<25)$ was performed with Chi-square test and a $\mathrm{P}$ value of less than 0.05 denotes statistical significance.

\section{RESULTS}

Two hundred pregnant women with high BMI $>25 \mathrm{~kg} / \mathrm{m}^{2}$ and two hundred pregnant women with normal BMI were selected and were followed prospectively.

\section{Maternal age distribution}

The age distribution in present study showed that about $50 \%$ of women with normal BMI are in the age group between 20 to 24 years and in the high BMI group about $43.5 \%$ fall in the age group between 20 to 24 years.

As age advances, the percentage of women in high BMI group are more than in normal BMI.

\section{Antepartum parameters}

\section{Abortion}

In present study, abortion was found to be more in high BMI group when compared to normal BMI group in accordance with the above studies but $\mathrm{p}$-value was found to be less than 0.05 , may be owing to the small size of the sample (Table 1). 
Table 1: Various complications occurring in women with normal BMI and high BMI.

\begin{tabular}{|c|c|c|c|c|c|c|}
\hline \multirow{2}{*}{ Complications } & \multicolumn{2}{|c|}{ Normal BMI } & \multicolumn{2}{|c|}{ High BMI } & \multirow{2}{*}{ P value } & \multirow{2}{*}{ Chi square } \\
\hline & $\mathbf{N}$ & $\%$ & $\mathbf{N}$ & $\%$ & & \\
\hline Preeclampsia & 16 & 8 & 56 & 28 & $<0.05$ & 27.1 \\
\hline GDM & 15 & 7.5 & 55 & 27.5 & $<0.05$ & 27.7 \\
\hline Oligo & 26 & 13 & 29 & 14.5 & 0.66 & 0.19 \\
\hline Abruption & 8 & 4 & 10 & 5 & 0.63 & 0.23 \\
\hline Anemia & 20 & 10 & 14 & 7 & 0.28 & 1.15 \\
\hline PROM & 26 & 13 & 28 & 14 & 0.77 & 0.09 \\
\hline
\end{tabular}

\section{Pre-eclampsia}

Present study showed an increased incidence of preeclampsia in patients with high BMI $(28 \%$ as compared to $8 \%$ of the normal BMI. p value was found to be less than 0.05 and was statistically significant in accordance with other studies.

\section{Gestational diabetes mellitus}

Present study showed a higher incidence of Gestational diabetes mellitus among women with high BMI with a value of $27.5 \%$ compared to a value of $7.5 \%$ in women with normal BMI.GDM on insulin was found to be $16.5 \%$ in the high BMI group and $1.5 \%$ in women with normal BMI. The p-value was found to be less than 0.05 and it was statistically significant.

\section{Oligohydramnios}

Oligohydramnios was found to occur in $13 \%$ of women with normal BMI and $14.5 \%$ of women with high BMI. It was found that oligohydramnios occurs independently of BMI and was not statistically significant.

\section{Abruption}

In present study, placental abruption was found to occur in $4 \%$ of normal BMI group and $5 \%$ of mothers in higher BMI group. the result was not statistically significant, not conforming with the following studies, may be due to a small sample size.

\section{Anaemia}

The incidence of anaemia in women with normal BMI was $10 \%$ and in high BMI was $7 \%$. $\mathrm{P}$ value was not statistically significant.

\section{Premature rupture of membranes}

In present study preterm delivery was found to be more in women with normal BMI with a value of $12.5 \%$ compared to the value of $6 \%$ in women with high BMI. As the p-value was less than 0.5 , it was found that preterm delivery and BMI were dependent on each other.

\section{Pre-eclampsia}

Table 2: Incidence of preeclampsia in normal BMI and high BMI.

\begin{tabular}{|l|l|l|l|l|}
\multirow{2}{*}{ Preeclampsia } & $\begin{array}{l}\text { Normal BMI } \\
\text { n=200 }\end{array}$ & \multicolumn{2}{l}{ High BMII } \\
& N & \% & N & \% \\
\hline Mild & 12 & 6 & 21 & 10.5 \\
\hline Severe & 4 & 2 & 35 & 17.5 \\
\hline Total & 16 & 8 & 56 & 28 \\
\hline
\end{tabular}

Chi square $=27.100, p=0.001(p<0.05)$

In present study, women with high BMI had $28 \%$ incidence of pre-eclampsia and those with normal BMI had $8 \%$ incidence (Table 2).

As the $\mathrm{p}$ value is less than 0.05 , BMI and pre-eclampsia was found to be dependent of each other.

\section{Gestational diabetes mellitus}

Table 3: Incidence of GDM in normal BMI and high BMI.

\begin{tabular}{|l|l|l|l|l|}
\hline \multirow{2}{*}{ GDM } & $\begin{array}{l}\text { Normal BMI } \\
\text { n=200 }\end{array}$ & \multicolumn{2}{l|}{ High BMI } \\
& $\mathbf{N}$ & $\mathbf{\%}$ & $\mathbf{N}$ & $\mathbf{\%}$ \\
\hline Meal plan & 12 & 6 & 22 & 11 \\
\hline Insulin & 3 & 1.5 & 33 & 16.5 \\
\hline Total & 15 & 7.5 & 55 & 27.5 \\
\hline
\end{tabular}

Chi square $=27.706, \mathrm{p}=0.001(\mathrm{p}<0.05)$

In present study, women with high BMI had $27.5 \%$ incidence of gestational diabetes mellitus and those with normal BMI had $7.5 \%$ incidence (Table 3).

As the p-value is less than 0.05, BMI and gestational diabetes mellitus were found to be dependent on each other.

\section{Induction of labour}

Among the patients with high BMI, the induction rate was $36.78 \%$ and for normal BMI, the induction rate was $26.39 \%$ (Table 4). 
Table 4: Induction of labour in normal BMI vs High BMI.

\begin{tabular}{|l|l|l|l|l|}
\hline & Normal BMI n=200 & High BMI n=200 \\
\hline Induced & $\mathbf{N}$ & $\mathbf{\%}$ & $\mathbf{N}$ & $\mathbf{\%}$ \\
\hline Not induced & 145 & 26.39 & 71 & 36.78 \\
\hline
\end{tabular}

\section{Mode of delivery}

The incidence of vaginal delivery, instrumental delivery and LSCS was found to be $57.5 \%, 9.5 \%$ and $31.5 \%$ respectively in women with normal BMI and $32.5 \%, 9.5 \%$ and $54.5 \%$ in women with high BMI respectively (Table $5)$.

Table 5: Mode of delivery in normal BMI vs high BMI.

\begin{tabular}{|l|l|l|l|l|l|l|}
\hline & \multicolumn{9}{l}{$\begin{array}{l}\text { Normal } \\
\text { BMI }\end{array}$} & \multicolumn{2}{l}{ High } & \multicolumn{2}{l|}{ BMI } & \multicolumn{2}{c|}{ Chi } \\
& N & \% & N & \% & value & square \\
\hline Vaginal & 115 & 57.5 & 65 & 32.5 & 0.001 & 25.25 \\
\hline Instrumental & 19 & 9.5 & 19 & 9.5 & 1 & 0 \\
\hline LSCS & 63 & 31.5 & 109 & 54.5 & 0.001 & 21.58 \\
\hline
\end{tabular}

The table shows that vaginal delivery and LSCS are dependent on BMI as their corresponding $\mathrm{P}$ value is found to be less than 0.05 .

\section{Postpartum complication}

The incidence of wound gaping in women with high BMI was found to be $4.5 \%$ and the incidence of women with low BMI was $1.5 \%$, the p-value was less than 0.05 (statistically significant) (Table 6).

Table 6: Various postpartum complications occurring in normal BMI and high BMI.

\begin{tabular}{|c|c|c|c|c|c|c|}
\hline \multirow[t]{2}{*}{ Complications } & \multicolumn{2}{|c|}{$\begin{array}{l}\text { Normal } \\
\text { BMI }\end{array}$} & \multicolumn{2}{|c|}{$\begin{array}{l}\text { High } \\
\text { BMI }\end{array}$} & \multirow{2}{*}{$\begin{array}{l}P \\
\text { value }\end{array}$} & \multirow{2}{*}{$\begin{array}{l}\text { Chi } \\
\text { square }\end{array}$} \\
\hline & $\mathbf{N}$ & $\%$ & $\mathbf{N}$ & $\%$ & & \\
\hline PPH & 11 & 5.5 & 7 & 3.5 & 0.335 & 0.931 \\
\hline Pyrexia & 1 & 0.5 & 2 & 1 & 0.562 & 0.336 \\
\hline Wound gaping & 3 & 1.5 & 9 & 4.5 & 0.079 & 3.093 \\
\hline Prolonged stay & 1 & 0.5 & 6 & 3 & 0.057 & 3.635 \\
\hline $\begin{array}{l}\text { Lactation } \\
\text { dysfunction }\end{array}$ & 0 & 0 & 5 & 2.5 & 0.024 & 5.063 \\
\hline
\end{tabular}

The incidence of lactational dysfunction in women with high BMI was found to be $2.5 \%$ and the incidence of women with low BMI was 0, the p-value was less than 0.05(statistically significant)

\section{Neonatal complication}

The incidence of preterm in babies born to mother with normal $\mathrm{BMI}$ is $12.5 \%$ and those born to high $\mathrm{BMI}$ is $6 \%$. the p-value is less than 0.05 . (statistically significant). The incidence of macrosomia in babies born to mother with normal BMI is $1 \%$ and those born to high BMI is $8.5 \%$. the p-value is less than 0.05.(statistically significant). The incidence of NICU stay in babies born to mother with normal BMI is $16.5 \%$ and those born to high BMI is $24.5 \%$. p-value is less than 0.05.(statistically significant).

\section{DISCUSSION}

Obesity is a growing epidemic and its effect on the outcome of pregnancy and delivery in the healthy population has not hitherto been extensively studied. This study aims to report the effect of maternal obesity on pregnancy complications with minimal confounding bias. ${ }^{5}$

This study adds to the increasing body of evidence which suggests that obesity, measured by BMI, predisposes women to complicated pregnancies and increased obstetric interventions. All pregnancies in obese women be acknowledged as high risk and managed according to strict guidelines. ${ }^{6}$ Management should include prepregnancy counselling to reduce weight; shared antenatal care and appropriate management of complications. The evidence for obesity as an important complication in pregnancy is mounting; it is time to inform practice based on this evidence. ${ }^{7}$

As age advances, the percentage of women with obesity seems to increase. Present study showed an increased incidence of pre-eclampsia in patients with high BMI ( $28 \%$ as compared to $8 \%$ of the normal BMI, which was statistically significant. $^{8}$ A higher incidence of Gestational diabetes mellitus among women with high BMI with a value of $27.5 \%$ compared to a value of $7.5 \%$ in women with normal BMI was seen and $16.5 \%$ in the high BMI group required insulin. In present study preterm delivery was found to be more in women with normal BMI with a value of $12.5 \%$ compared to the value of $6 \%$ in women with high BMI. Caesarean delivery was found in $54.5 \%$ of the high BMI mothers compared to $31.5 \%$ in normal BMI mothers, statistically significant. ${ }^{9}$ Vaginal delivery was found to occur more in normal BMI mothers with a percentage of 57.5 compared to $32.5 \%$ in the high BMI group. The most common indication for Caesarean in high BMI mothers was cephalo-pelvic disproportion $(27.62 \%)$. In present study, pyrexia was found in $1 \%$ of mothers with high BMI and wound gaping was found with an incidence of $4.5 \%$ in high BMI mothers with a p-value of 0.079 (statistically significant). There was prolonged stay in $3 \%$ of mothers with high BMI and lactational dysfunction was found in $2.5 \%$ (p $<0.05)$.

IUGR was found in $10 \%$ of babies of women with high BMI. Still birth occurred in $2.5 \%$ of deliveries of high BMI mothers compares to $0.5 \%$ in mothers of normal BMI group. Maternal obesity more often leads to 
intrauterine fetal death. NICU admission was found in $24.5 \%$ of babies born to mothers with high BMI compared to $16.5 \%$ of babies born to mothers with normal BMI with a significant p-value of less than $0.05 .^{10}$

\section{CONCLUSION}

The inference from present study is that the obstetric and neonatal complications are more in women with high body mass index and obesity, which pose a challenge to the obstetrician. Counselling women about pre-pregnancy loss of weight, healthy food and exercise, and healthy life style pattern during pregnancy is prudent for a health pregnancy.

Funding: No funding sources Conflict of interest: None declared

Ethical approval: The study was approved by the Institutional Ethics Committee

\section{REFERENCES}

1. WHO. Obesity: preventing and managing the global epidemic. Report of a WHO Consultation. WHO Technical Report Series 894. Geneva: World Health Organization, 2000.

2. Who EC. Appropriate body-mass index for Asian populations and its implications for policy and intervention strategies. Lancet (London, England). 2004;363(9403):157.

3. National Family health survey, India. Available at http://rchiips.org/nfhs/nutrition_report_for_website_ 18sep09.pdf
4. Kiran TU, Hemmadi S, Bethel J, Evans J. Outcome of pregnancy in a woman with an increased body mass index. BJOG: Int J Obstet Gynecol. 2005;112(6):768-72.

5. Edwards LE, Hellerstedt WL, Alton IR, Story M, Himes JH. Pregnancy complications and birth outcomes in obese and normal-weight women: effects of gestational weight change. Obstet Gynecol. 1996;87(3):389-94.

6. Crane SS, Wojtowycz MA, Dye TD, Aubry RH, Artal R. Association between pre-pregnancy obesity and the risk of cesarean delivery. Obstet Gynecol. 1997;89(2):213-6.

7. American College of Obstetricians and Gynecologists: Obesity in pregnancy. Committee Opinion No. 315, Obstet Gynecol. 2005;106(3):6715 .

8. Sebire NJ, Jolly M, Harris JP, Wadsworth J, Joffe M, Beard RW, Regan L, Robinson S. Maternal obesity and pregnancy outcome: a study of 287213 pregnancies in London. Int J Obes. 2001;25(8):1175.

9. Galtiere-Dereure F, Montpeyroux F, Boulot P, et al. Weight excess before pregnancy: complications and cost. Int J obes. 1995:19(7):443-448.

10. Ehrenberg H, Mercer B, Catalano P. The influence of obesity and diabetes on neonatal macrosomia. Am J Obstet Gynecology. 2003;189(6):S107.

Cite this article as: Hemalatha N, Shanthini. Maternal body mass index and feto-maternal outcome: a comparative study. Int J Reprod Contracept Obstet Gynecol 2019;8:840-4. 